\title{
The Usage of Videogame as a Physiotherapeutic Intervention in Individuals with Down Syndrome
}

\author{
Barbara Beatriz Joei Mioto, Cristiane Gonçalves Ribas \\ School of Health and Biosciences, Pontifícia Universidade Católica do Paraná, Curitiba, Brazil \\ Email: barbara.mioto@gmail.com
}

Received 8 July 2014; revised 22 August 2014; accepted 24 September 2014

Copyright (C) 2014 by authors and OALib.

This work is licensed under the Creative Commons Attribution International License (CC BY). http://creativecommons.org/licenses/by/4.0/

(c) (i) Open Access

\section{Abstract}

Down syndrome (DS) is a genetic disease which has a set of characteristics that result in delays of basic motor skills. Physiotherapy aims to reduce delays in gross and fine motor skills. It also aims to prevent joint instabilities and deformities of the bones. A feature that has drawn the attention of therapists includes virtual reality as a method of rehabilitation. The goal of this study is to analyze the degree of effectiveness of the usage of the game in the rehabilitation of patients with Down syndrome. We have selected five volunteer students; on the attendances, we use Nintendo Wii and Wii Sports CD, which contains tennis, bowling, boxing, baseball and golf games. In addition to, the assessments were executed at the first and at the last attendances for comparison of results. The results were individually placed into charts, and it could be remarkable the evolution of the aspects was evaluated. We conclude that virtual reality, as an additional treatment, is interactive, playful and serves as an additional motivation for physical therapy appointments, and it gives the therapists an extra tool to assess and to acquire skills. We suggest further studies with a higher number of participants to give statistically meaning results regarding the use of videogame in therapies.

\section{Keywords}

Down Syndrome, Virtual Reality, Motor Delay, Wii, Physiotherapy

Subject Areas: Kinesiology, Pediatrics

\section{Introduction}

Down syndrome (DS) is a chronic condition caused by a chromosomal abnormality that occurs, on average, in 1 to every 700 - 800 live births [1], and in Brazil, the incidence is of 1.13:1000 live births [2]. Patients with DS 
admittedly have higher mortality rates in the first years of life when compared to the general population, attributing this to the increased frequency of internal malformation defects [3]. Scientific and technological advances have significantly improved the survival of these children. (...) Regarding to the development of motor skills, the evidence reveals that these children have a delay in the acquisition of basic motor milestones, indicating that these landmarks emerge in a different time (higher) than the children with normal development [4].

Physiotherapy seems to be paramount in the conditions in which the involvement is motor and also during the monitoring of children with mental disabilities, such as Down syndrome. The objectives of physical therapy for children suffering with Down syndrome are: to reduce delays in gross and fine motor skills, facilitating and stimulating the postural reactions necessary for the performance of the steps of normal development, and the prevention of joint instabilities and bone deformities [5].

A feature that has caught the attention of therapists includes virtual reality as a method of rehabilitation. It is believed that the use of virtual reality can be quite effective in the rehabilitation of neurological patients, as it offers the opportunity to experience different situations in an individualized way; it encourages the active participation of the patient and facilitates the study of the characteristics of skills and perceptual and motor abilities of the patient. Furthermore, there is the possibility of immediate feedback from the patient, in other words, while interacting with the virtual world, the patient gets immediate feedback of his actions efficiency [6].

\section{Material and Methods}

To develop this study, five volunteers with Down syndrome have been selected from a special school; they were with ages between 8 and 14 years old, of both sexes, with 80\% participation in the project. This occurred upon signing the informed consent of the guardians of the participants, with explanation of the objectives, procedures, risks and benefits of the same, according to Resolution 196/96 of the National Health Council. Exclusion criteria were presence of associated brain injury, blood pressure (BP) uncontrolled, dyspnea upon exertion, use of psychotropic drugs (benzodiazepines), presentation of disease during the project, participation in another program of physical activity and physiotherapy or dropout statement.

The materials used were a Nintendo Wii video game system; 42 inch LG LCD TV; "Wii Sports" CD games; adapted psychomotor evaluations for 6 - 10 years old (Appendix); texts and articles for references.

In total, 26 attendances were accomplished, so that the first and last have been reserved for the assessment. The sessions occurred during 30 minutes each and were made twice a week at their own school.

The games that were used with the patients were tennis, baseball, bowling, golf and boxing.

The ratings used were adapted to focus on some specific psychomotor functions (gross motor coordination, lateral dominance, body schema and memories). According Brêtas et al. [7], this instrument for data collection was based on the Psychomotor Examination Manual and the Manual of Rossel Psychomotor Review Guilmain.

For the assessment of gross motor skills, 17 items were arranged. The patients had to fulfill each of them, and they were evaluated according to the degree of difficulty during its execution. The responses were divided into: a) yes, made without difficulty, b) yes, made with difficulty and c) not performed. The same was done for the analysis of lateral dominance, in which the tests were divided into three parts: the recognition of right/left in himself, the execution of movements verbally ordered and the recognition of right/left on the other person. The body schema, in turn, was divided into four items. Regarding memory, visual and tactile memories were the ones evaluated.

The results achieved were placed individually in the form of graphs so that it is possible to compare the first and the last assessment.

\section{Results}

After application and tabulation of the data obtained, it was evident the evolution of the children's responses to gross motor coordination, to body schema, to the memories and to the handedness of individuals.

Figure 1 shows items (\%) of gross motor coordination that were performed without difficulty in the first and last assessment, respectively. It is observed that the individual 1 held $76.5 \%$ of the items without difficulty; individuals 2 and 3 performed 58.8\%, the individual 4 held only 35.3\% and the children number 5 has performed $52.9 \%$ of the items. Nevertheless, in the last assessment made after 24 calls, most of the items were done without difficulty, while the lowest rate was restricted to the individual 4 , which held $82 \%$ of the items.

Figure 2, in turn, presents the responses (\%) related to the memory test. It is observed in the first evaluation 


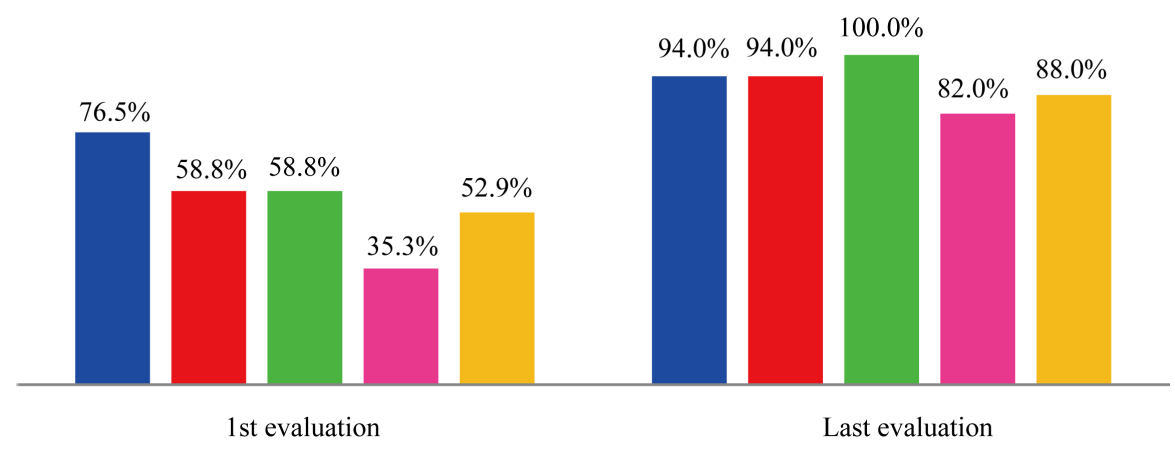

Figure 1. Gross motor coordination-items from evaluation performed without difficulty.

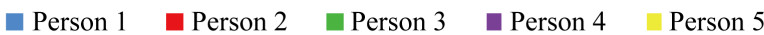

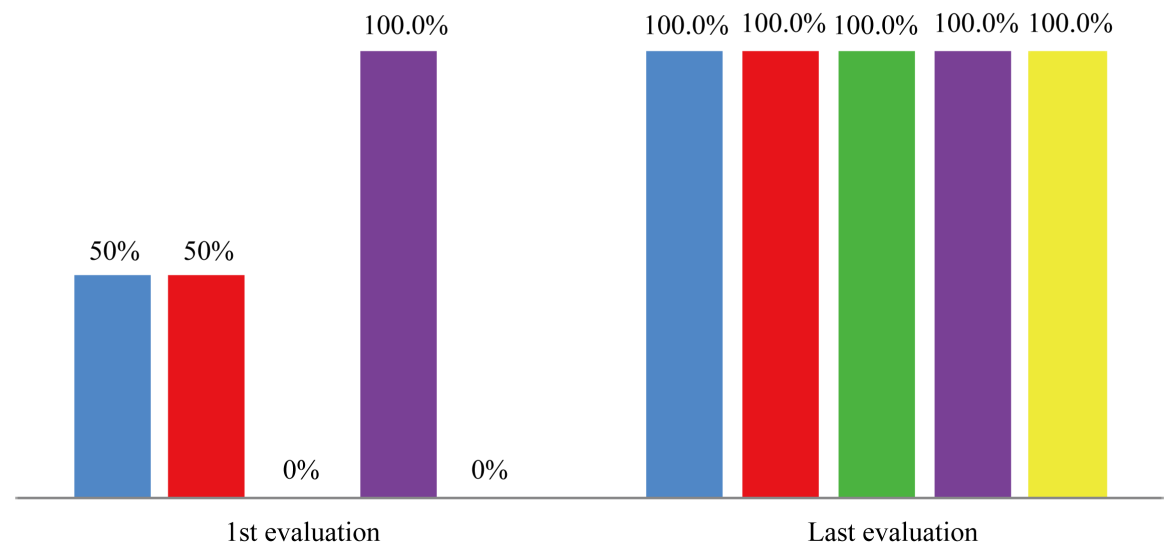

Figure 2. Memories—items from evaluation performed without difficulty.

that only one patient has perfectly performed the exercises regarding tactile and visual memory. Moreover, two individuals were able to perform well only the exercises that were related to one of these memories, and the other two failed to perform any of the exercises. After the sessions, however, all subjects were able to perform the tests without any difficulty.

Observing Figures 3-5, it can be noted that excepting person number 5, all individuals that in the first evaluation performed $0 \%$ of laterality activities proposed in the assessment, in the second one they were already able to perform all activities without difficulty.

Regarding the body scheme, almost all children have performed $100 \%$ of the activities during the first and the last evaluation, without difficulties. In the first evaluation, the individual 5 failed to achieve one of the 4 items proposed, and has easily performed the other 3 activities. Nevertheless, in the last assessment, the individual was able to perform the item, although it has been done with some difficulty.

\section{Discussion}

We know that when it comes to Down syndrome (DS), intrinsic constraints such as muscular hypotonia and joint hypermobility contribute to delayed motor development, for delays in performance of movements and changes in postural control. These characteristics reduce the possibility of motor experiences and exploration of the environment, which affect the performance of motor skills [8]. Such traits are observed in the results of the first evaluation of gross motor coordination. 


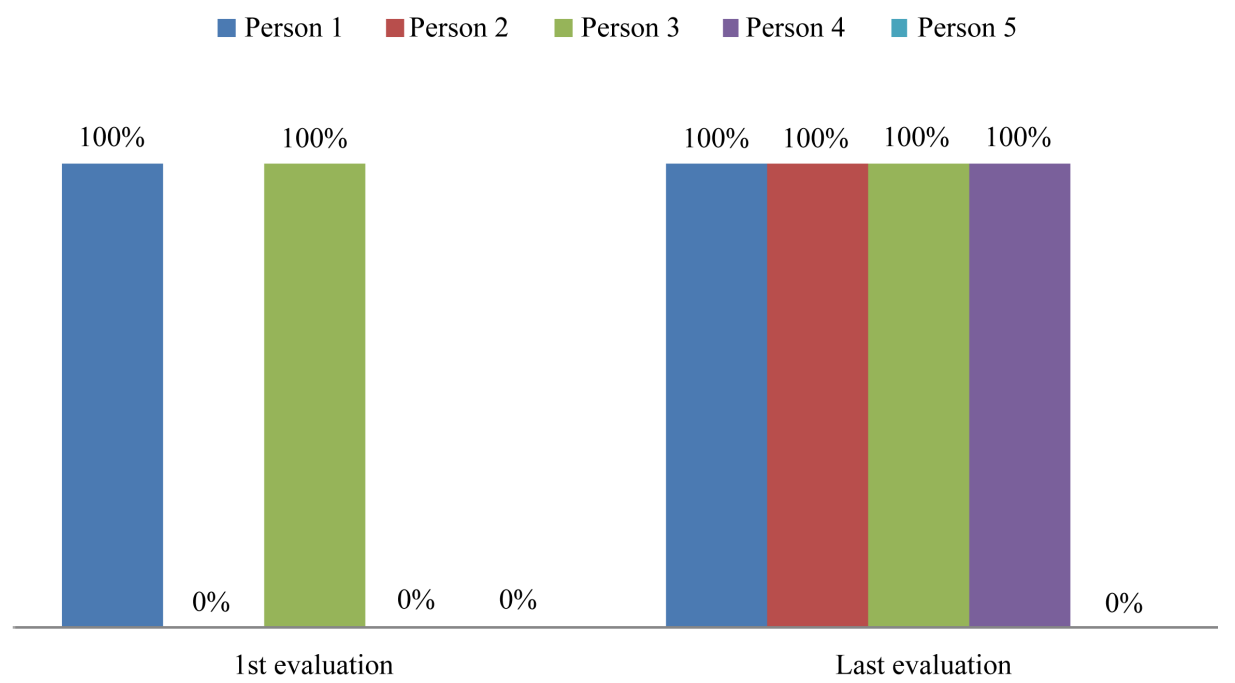

Figure 3. Left-right discrimination: recognition about themselves.

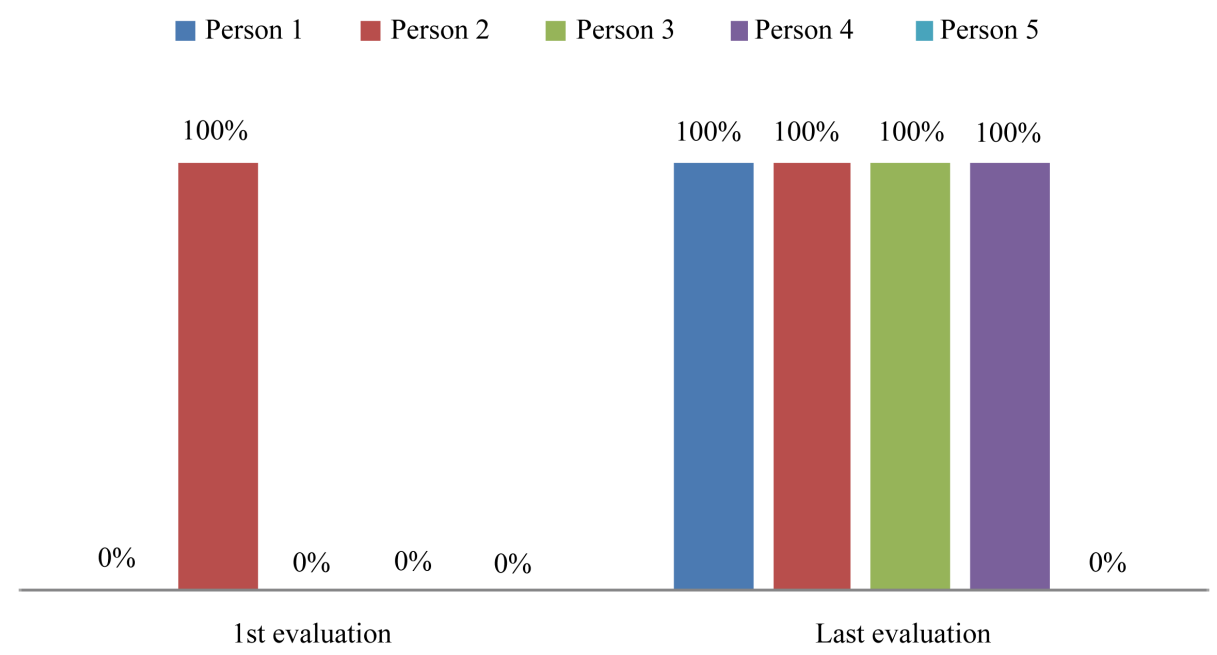

Figure 4. Left-right discrimination: verbally ordered execution of movements.

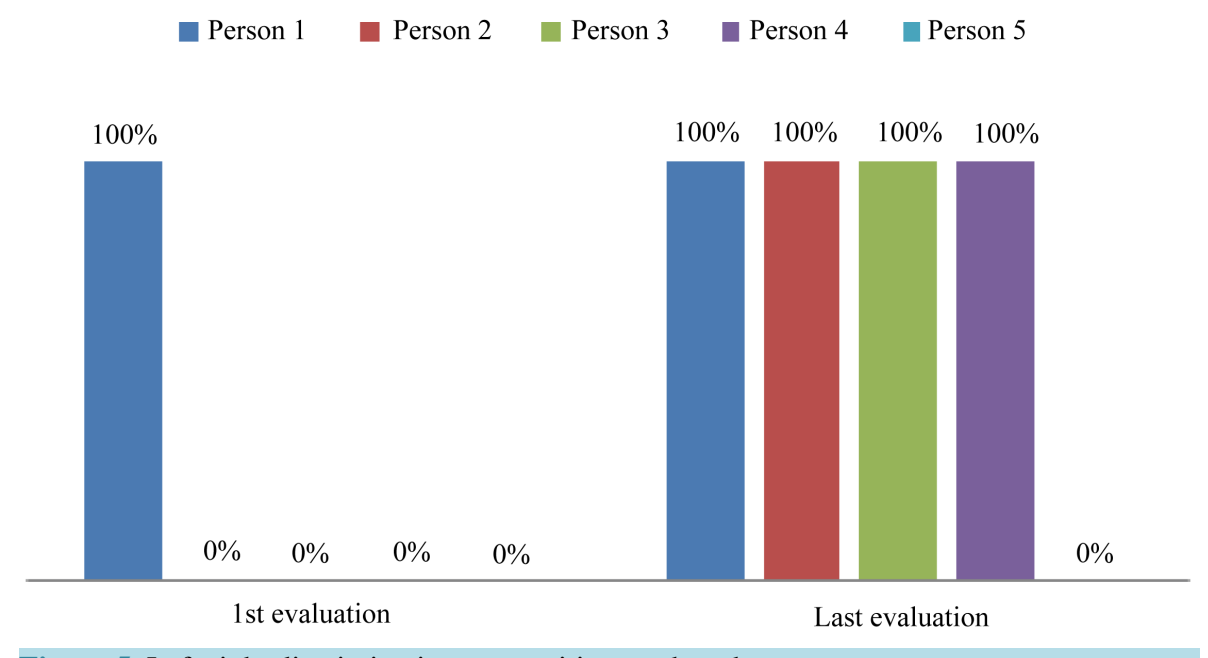

Figure 5. Left-right discrimination: recognition on the other person. 
From this, children began to be weekly stimulated through the games proposed in the Nintendo Wii game.

One of the games used was tennis. According to Balbinotti [9], tennis involves several types of skills, among them, the locomotor skills, including all variations of displacements; stabilizer skills, when the situation requires some degree of static or dynamic balance to achieve accuracy in blows; and manipulative skills, which guarantee the batting. Through this sport, it was possible to work one-leg balance, left-right discrimination, trunk rotation and decreased base of support.

The second proposed game was bowling. According to Cardoso et al. [10], laterality is one aspect for which the bowls can contribute, once it helps the child to understand the difference between right and left, and also can help the child to recognize the order in a box and properly follow the graphical direction, which is the key for reading activities.

Moreover, it is still possible to make a child recognize positions, directions, distance, size and shape of moving bodies, contributing to the development of his/her spatial awareness.

In addition, the golf game has been used to stimulate trunk rotation, weight bearing, and the reduction of base of support. Further, with boxing we could stimulate the reduction of the base of support, the rotation of the trunk, the agility for dodging from blows and the dynamic balance. Baseball, meanwhile, could stimulate agility, ability to bounce, rotation of the trunk and weight bearing.

Some very peculiar lifestyle aspects of people with Down syndrome are related to physical inactivity, use of drugs and unbalanced eating habits, and these determinants can lead to appearance of various pathologies and/or disorders, from which obesity is highlighted [11]. This reflects the importance of encouraging the practice of dynamic activities with these individuals, whether real or virtual.

Junior et al. [12] stated in his study that there was improvement in motor skills of people with post-stroke sequelae, with an average age of 58, after undergoing training of eight sessions of virtual reality therapy for simulating complex tasks, integrating movements in joints of the shoulder, elbow, wrist and metacarpophalangeal joints. This suggests the effectiveness of virtual reality on the motor training.

The rehabilitation with the use of virtual technology seems to be useful, especially with regard to the motivation of patients in some treatment modalities. For body balance, the use of virtual reality has also been proving effectiveness [12].

In a study directed by Pavão et al. [13], virtual reality was also used to stimulate balance in post-stroke patients, and physical demand imposed by the virtual reality through the game seems to have provided stimuli for individuals to extend their movements on the bases of support, assisting them in a better exploitation of their base and increasing proprioceptive afferents to maintain stability.

In addition to using visual feedback, some virtual reality systems provide audio information, which increases the temporal perception during task-oriented, facilitating, also, the control of postural balance [12].

Therefore, according to some studies and to the present study, it is remarkable the improvement of aspects of gross motor skills, memories, right-left discrimination and body schema from the use of video games as a form of physical therapy intervention in patients with Down syndrome.

\section{Conclusion}

The results of this study demonstrate that when laterality training, balance, gross motor coordination, body schema and memory are worked through Nintendo Wii video game stimulation, it provides significant results in physical therapy rehabilitation. Thus, virtual reality can be considered one more resource for treatment, besides being interactive, entertaining, and an additional motivation during physical therapy sessions. Although literatures related to the use of video game and its therapeutic intervention is scarce, it has been increasingly common for its practice in the rehabilitation process, which makes its proof important. Due to the low number of participants for this study, the videogame can be only considered an extra resource for rehabilitation. However, it is suggested further studies with a higher number of participants to provide statistically meaningful results regarding the efficacy of videogame as a method of rehabilitation (and not only an extra resource).

\section{References}

[1] Nunes, D.R. and Dupas, G. (2011) Independência da criança com síndrome de Down: A experiência da família. The Revista Latino-Americana de Enfermagem, 19, 1-9.

[2] Lorena, S.H.T. (2012) Síndrome de Down: Epidemiologia e alterações oftalmológicas. Revista Brasileira de Oftal- 
mologia, 71, 188-190. http://dx.doi.org/10.1590/S0034-72802012000300009

[3] Boy, R., Neto, J.G.B., Vargas, F.R., Fontana, C., Almeida, J.C.C. and Llerena Junior, J. (1995) Síndrome de DownAnálise clínica, citogenética e epidemiológica de 165 casos. Journal of Pediatrics, 71, 88-92.

http://bases.bireme.br/cgi-bin/wxislind.exe/iah/online/?IsisScript=iah/iah.xis\&src=google\&base=LILACS\&lang=p\&ne xtAction=lnk\&exprSearch=175961\&indexSearch=ID http://dx.doi.org/10.2223/JPED.720

[4] Mancini, M.C., Silva, P.C., Gonçalves, S.C. and Martins, S.M. (2003) Comparação do desempenho funcional de crianças portadoras de síndrome de Down e crianças com desenvolvimento normal aos 2 e 5 anos de idade. Arquivos de Neuro-Psiquiatria, 61, 409-415. http://dx.doi.org/10.1590/S0004-282X2003000300016

[5] Ribeiro, C.T.M., Ribeiro, M.G., Araújo, A.P.Q.C., Torres, M.N. and Neves, M.A.O. (2007) Perfil do atendimento fisioterapêutico na Síndrome de Down em algumas instituições do município do Rio de Janeiro. Revista Neurociências, 15, 114-119. http://www.revistaneurociencias.com.br/edicoes/2007/RN\%2015\%2002/Pages\%20from\%20RN\%2015\%2002-4.pdf

[6] Schiavinato, A.M., Baldan, C., Melatto, L. and Lima, L.S. (2010) Influência do Wii Fit no equilíbrio de paciente com disfunção cerebelar: Estudo de caso. Journal of the Health Sciences Institute, 28, 50-52. http://www.unip.br/comunicacao/publicacoes/ics/edicoes/2010/01_jan-mar/V28_n1_2010_p50-52.pdf

[7] Brêtas, J.R.S., Pereira, R.S., Cintra, C.C. and Amirati, K.M. (2005) Avaliação de funções psicomotoras de crianças entre 6 e 10 anos de idade. Acta Paulista de Enfermagem, 18, 403-412.

[8] Coppede, A.C., Campos, A.C., Santos, D.C.C. and Rocha, N.A.C.F. (2012) Desempenho motor fino e funcionalidade em crianças com síndrome de Down. Fisioterapia e Pesquisa, 19, 363-368.

[9] Paula, P.R. and Balbinotti, C. (2009) Iniciação ao tênis na infância: os primeiros contatos com a bola e a raquete. In: Balbinotti, C. and Berleze A., Eds., O ensino do tênis: Novas perspectivas de aprendizagem, Artmed, Porto Alegre, 1528.

[10] Cardoso, F.B., Machado, S.E. and Morra, R. (2004) A prática do boliche como elemento facilitador da aprendizagem. http://www.boliche.com.br/criticas/melhorar037.htm

[11] Neto, J.F., Pontes, L.M. and Filho, J.F. (2010) Alterações na Composição corporal decorrentes de um treinamento de musculação em portadores de síndrome de Down. Revista Brasileira de Medicina do Esporte, 16, 9-12. http://dx.doi.org/10.1590/S1517-86922010000100001

[12] Junior, R.S.M., Carvalho, R.J.P., Silva, E.B. and Bastos, F.G. (2011) Efeito da reabilitação virtual em diferentes tipos de tratamento. Revista Brasileira de Ciências da Saúde, 9, 56-63. http://seer.uscs.edu.br/index.php/revista_ciencias_saude/article/view/1331/1065

[13] Pavão, S.L., Sousa, N.V.C, Oliveira, C.M., Castro, P.C.G. and Santos, M.C.M. (2013) O ambiente virtual como interface na reabilitação pós-AVE: Relato de caso. Fisioterapia em Movimento, 26, 455-462. http://dx.doi.org/10.1590/S0103-51502013000200022 


\section{Appendix}

\section{Assessment of Psychomotor Functions}

IDENTIFICATION:

Name:

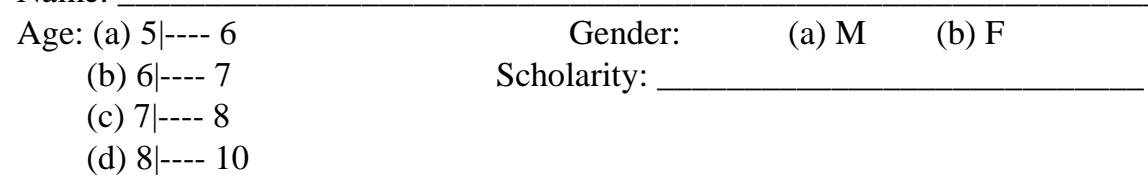

\section{I-MOTOR FUNCTION}

\section{Fine motor coordination}

(a) Yes, performed without difficulty (b) Yes, performed with some difficulty (c) Not performed

1. ( ) docking attitude

2. ( ) sticking attitude

3. ( ) articulated composition of 10 clips

4. ( ) buttoning and unbuttoning a line of buttons

5. ( ) pull a zipper

6. ( ) piling attitude

7. ( ) paper snipping (use models)

8. ( ) drawing labyrinths (use models)

2. Gross motor coordination, body dynamics, posture and balance

(a) Yes, performed without difficulty (b) Yes, performed with some difficulty (c) Not performed

1. ( ) control of immobility for $30 \mathrm{sec}$ (with eyes opened).

2. ( ) control of immobility for $30 \mathrm{sec}$ (with eyes closed).

3. ( ) static balance on one leg during 30 sec.

4. ( ) walk forward, in a straight pathway.

5. ( ) walk backward.

6. ( ) jump with both feet together, without moving.

7. ( ) hops on one foot at a distance of 2 meters.

8. ( ) hurdle.

9. ( ) crouch.

10. ( ) clap hands-feet-hands (movement dissociation)

11. ( ) hitting ball.

12. ( ) kick a stationary ball.

13. ( ) kick a rebounding ball.

14. ( ) skip rope.

15. ( ) accompany with eyes, a circle made with the examiner's hand, without moving head.

16. ( ) arms horizontally extended on the sides describing circles in space with indicators of the hands (the right on the clockwise direction, and the left on the counter clockwise direction)—10 sec of duration.

17. ( ) walking, the child carries in his/her left hand a coil from which (s)he unrolls the wire, in order to roll it in his/her right indicator. After 5 to $10 \mathrm{sec}$ of rest, repeat it with the other hand-15 sec of duration.

\section{II-PERCEPTUAL FUNCTION}

\section{Body schema}

(a) Yes, performed without difficulty (b) Yes, performed with some difficulty (c) Not performed

1. ( ) nominate parts of the body itself

2. ( ) nominate parts of the body in the others

3. ( ) discriminate body parts in the objects

4. ( ) human figure drawing 
4. Spatial adaptation (walk in a determined pathway, counting until 5 steps and come back counting 10 steps, for 3 times).

(a) Yes, performed without difficulty (b) Yes, performed with some difficulty (c) Not performed

1. ( ) smaller steps

2. ( ) larger steps

\section{Spatial orientation}

(a) Yes, performed without difficulty (b) Yes, performed with some difficulty (c) Not performed ( ) realization of the game hand-foot

\section{Memories}

(a) Yes, performed without difficulty (b) Yes, performed with some difficulty (c) Not performed

1. ( ) visual memory

2. ( ) tactile memory

\section{Rhythm and concentration}

(a) Yes, performed without difficulty (b) Yes, performed with some difficulty (c) Not performed 1. ( ) Spontaneous rhythm (spontaneous time).

2. ( ) Coded pace (temporal structure).

\section{STAMBACK TEST OF RHYTHM AND CONCENTRATION OF SIGHT}

\begin{tabular}{|c|c|c|c|c|}
\hline Rhythmic structures & incorrect & \multicolumn{2}{|l|}{ correct } & \\
\hline 1. & o $\quad 0$ & $(\quad)$ & ( & ) \\
\hline 2. & оoо & $(\quad)$ & ( & ) \\
\hline 3. & оoоo & $(\quad)$ & ( & ) \\
\hline 4. & o $\quad$ oo & $(\quad)$ & ( & ) \\
\hline 5. & о оо & $(\quad)$ & ( & ) \\
\hline 6. & o 000 & $(\quad)$ & ( & ) \\
\hline 7. & оо оо & $(\quad)$ & ( & ) \\
\hline 8. & 000000 & $(\quad)$ & ( & ) \\
\hline 9. & ooooo & $(\quad)$ & ( & ) \\
\hline 10. & oooo & $(\quad)$ & ( & ) \\
\hline 11. & o 0000 & $(\quad)$ & ( & ) \\
\hline 12. & $0000 \quad 0$ & $(\quad)$ & ( & ) \\
\hline 13. & оо 0 оо & $(\quad)$ & ( & ) \\
\hline 14. & oooooo & $(\quad)$ & ( & ) \\
\hline 15. & 00000 & $(\quad)$ & ( & ) \\
\hline 16. & $00000 \quad 0$ & $(\quad)$ & ( & ) \\
\hline 17. & o 000000 & $(\quad)$ & ( & ) \\
\hline 18. & оо 0000 & $(\quad)$ & ( & ) \\
\hline 19. & ooo $000 \quad 0$ & $(\quad)$ & ( & ) \\
\hline 20. & o $0000 \quad$ o oo & $(\quad)$ & ( & ) \\
\hline & Total: & 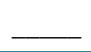 & 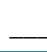 & - \\
\hline
\end{tabular}

\section{Discrimination of left/right}

(a) Yes, performed without difficulty (b) Yes, performed with some difficulty (c) Not performed 
1. Left-right: recognition of itself.

1. () Show the right hand

2. () Show the left hand

3. () Show the right eye

4. () Show the left ear

2. Executemovements ordered orally.

1. ( ) Right hand-left ear

2. ( ) Right hand-left eye

3. ( ) Left Hand-Right Eye

4. ( ) Left Hand-Right Ear

3. Right-Left: Recognition in the other (of the observer facing forward).

1. ( ) Touch in my left hand

2. ( ) Touch in my right hand

9. Rhythmic-perceptual spelling (use graphical models): (a) yes (b) no

1. ( ) Consistency of rhythm

2. ( ) Inversions of direction

3. ( ) Confusions of order

4. ( ) Model Changes

5. ( ) Inexact Reproduction

6. ( ) Irregular Size

\section{III-HANDEDNESS (Lateralization)}

10. Assessment of handedness: (a) yes (b) no

1. ( ) defined handedness

2. ( ) crossedlateral dominance

3. ( ) indefinite dominance side

\begin{tabular}{cccc|}
\hline HANDS & Right & Left & Indefinite \\
\hline Evidence & & \\
Snip & & \\
Pack & & \\
Hands moving in range & & \\
Puppets with hands & & \\
Movement of the fingers-piano & & \\
Drawing & Right & \\
EYES & & \\
Evidence & & \\
Punched card & & \\
Looking through the cone & Indefinite \\
FEET & & \\
Evidence & & \\
Static balance & & \\
Dynamic balance & & \\
Kick & & \\
Rebound & & \\
Climbing the chair & & \\
Out of the chair & & \\
& & \\
\end{tabular}

